\title{
Editorial
}

6

\section{Envejecer y cuidar..., ¿en pueblo o en ciudad?}

Hace pocas fechas me topé entre las páginas de mi periódico local con un titular que rezaba así: "Abandonados en los pueblos", haciéndose eco de un reciente estudio acometido sobre las necesidades de las personas de edad y sus familias con gran discapacidad en el medio rural, y, sin terminar de leer lo que recogían sus líneas, empecé a dar forma a esta tribuna reflexiva que comparto cada trimestre con ustedes, fieles compañeros de viaje.

Muchos de nosotros, habitantes de ciudades de mediano o gran tamaño (ambas con notables diferencias, pero envueltas cada vez más en ruidos tumultuosos, precipitaciones agónicas, impersonalizaciones imperdonables), aspiramos a salir al medio rural en cuanto el trabajo nos lo permite, a adquirir alguna pequeña vivienda en esos lares, donde se respira, en contra de lo descrito, el silencio, la tranquilidad, la vida nominal, pero considerando que el domingo has de regresar, o que las vacaciones hoy por hoy, son finitas, consolándonos finalmente con la idea de que "cuando me retire no tendré que volver a marcharme".

Sin duda esta percepción que les puede sonar familiar y cercana, este panorama adulador e ilusionante (que hace que las semanas, los meses y los años se acorten) tiene el marco de una aspiración al tiempo del retiro laboral, sin aventurar ninguna otra merma que pueda contaminar ese sueño, pero la realidad nos dicta al respecto cartas muy distintas.

Desde este panorama onírico y urbano, de maduros aún distantes de la vejez declarada, con un prisma gerontológico nunca enfocado hacia nosotros mismos, vemos un escenario enormemente acogedor para envejecer, para adentrarnos en las fauces desconocidas de las "últimas décadas", siempre que no medie la falla en la salud, la falta de tu pareja, las grandes necesidades de cuidados y cuidadores.

Ese sin duda es el hábitat natural e imperecedero para las personas que siempre han vivido allí, pero que también, conforme pasa el tiempo, ven orbitar sobre ellos las mismas amenazas descritas para los forasteros que vienen a retirarse. La corte de cuidados de los lugareños se inscribe en las propias actas del ayuntamiento (es vecino de aquí, padre o hermano de tal y de cual, amigo que fue de mi padre o tío...) y en los códigos familiares en los que se inscriba (siempre y cuando no haya perdido a estos por fallecimiento o éxodo laboral).

Es en este sentido en el que se abre una gran dualidad, para ambos grupos de envejecientes y sus potenciales cuidadores, y dos escenarios enteramente contrapuestos.

No tienen parangón las ventajas emocionales y la calidad de vida a la que puede aspirar una adulto mayor en el medio rural, incluso la red de apoyo brindada por los vecinos y amigos (de siempre o recientes) en ausencia de la familia, siempre y cuando sus necesidades no sobrepasen lo puntual y esporádico, lo extraordinario, al igual que las necesidades de custodia sanitaria no sobrepasen los recursos de la atención primaria de salud, de extensa red hoy por hoy en toda la geografía. Es decir, a mi entender, aun pudiendo carecer de ciertos recursos de ocio e iniciativas culturales y formativas, el espacio rural ofrece todas las virtudes para envejecer, siempre y cuando disfrutes de un nivel elevado de salud, cifrado en clave gerontológica, en autonomía e independencia, unas moderadas necesidades de cuidados personales y una suficiencia económica que permita cubrir dignamente tu supervivencia.

Pero el análisis de la vida cotidiana cambia radicalmente cuando en ese cuerpo viejo, habitante rural (con distinta magnitud en razón de la ubicación y comunicación de éste) se radicaliza la expresión de procesos de enfermedad y la discapacidad se hace cada vez más presente. Las necesidades de cuidados básicos, la supervisión e intervención sanitaria, la accesibilidad a diferentes servicios y recursos sociales y sanitarios, se ve ensombrecida por un desabastecimiento que puede hacer difícil la supervivencia y mancillar la magnífica prensa que apostaba por estos lugares para pasar el final de tus días.

No se puede consentir aceptar resignadamente que aquel mayor frágil, dependiente, desubicado de una ciudad de tamaño medio, viva sus últimos días con tenues paños calientes que no cubran sus más elementales necesidades, o pase la solución por articular una caravana de mayores que fijen su residencia en casa de familiares o instituciones urbanas, cuando su deseo es no perder su domicilio.

¿Es posible reforzar, ordenar y distribuir los resortes y recursos para vencer esta situación de "abandono en los pueblos" que están sufriendo los más viejos y discapacitados? Desde la recién aprobada Ley de Dependencia, ¿̨es una pretensión desmesurada arbitrar ayudas específicas a los cuidadores familiares en esos ámbitos geográficos -como zonas de elevado riesgo- que quieran seguir cuidando de los suyos? ¿Será una utopía, como se hiciera con el sistema de agrupación escolar en zonas despobladas, poner en marcha con creatividad recursos de ayuda para esos más aislados y "abandonados"?

Cuando empecé a pasar algunos ratos de ocio en ese paraíso para envejecer, perdí de vista rápidamente la posibilidad de una vejez dependiente, que ahora aflora.

J. Javier Soldevilla Agreda Director de Gerokomos 